COMECHINGONIA REVISTA DE ARQUEOLOGIA

10 


\section{Índice}

1. Recordando a Nicolás de la Fuente.

Por: Bonofiglio, Marta

2. La Construcción del espacio funerario en la Ciénaga (Catamarca).

Por: Balesta, Bárbara

3. Dieta y sociedades agropastoriles: análisis de isótopos estables de un sitio de la Puna Meridional Argentina (Antofagasta de la Sierra, Catamarca).

Por: Aranibar, Julieta; Sara M. L. López Campeny; M. Gloria Colaneri; Andrés S. Romano;

Stephen A. Macko y Carlos A. Aschero

4. Procedencia de artefactos de obsidiana de contextos arqueológicos de Antofagasta de la Sierra (ca. 4500-3500 AP).

Por: Escola, Patricia S. y Salomón Hocsman

5. Cazadores-recolectores de las sierras de Córdoba. Una mirada desde el sitio El Alto 3 (Pampa de Achala, Córdoba).

Por: Rivero, Diego

6. Las sociedades formativas tardias del Valle Fértil, San Juan.

Por: Cahiza, Pablo 


\title{
DIETA Y SOCIEDADES AGROPASTORILES: ANÁLISIS DE ISÓTOPOS ESTABLES DE UN SITIO DE LA PUNA MERIDIONAL ARGENTINA (ANTOFAGASTA DE LA SIERRA, CATAMARCA) ${ }^{1}$
}

\author{
Araníbar, Julieta ${ }^{1, *}$; Sara M. L. López Campeny"; M. Gloria Colaneri ${ }^{3}$ \\ Andrés S. Romano ${ }^{3}$; Stephen A. Macko ${ }^{1}$ y Carlos A. Aschero ${ }^{2}$
}
${ }^{1}$ Department of Environmental Sciences, University of Virginia, USA. *Actualmente CONICET- Instituto Argentino de Nivología, Glaciologia y Ciencias Ambientales (IANIGLA)
${ }^{2}$ CONICET-Instituto de Arqueología y Museo (IAM), Instituto Superior de Estudios Sociales (ISES), Universidad Nacional de Tucumán.
${ }^{3}$ IAM, Universidad Nacional de Tucumán

Presentado el: 01/11/2006 - Aceptado el: 29/03/2007

\section{Resumen}

Se presentan los resultados obtenidos a partir del análisis de isótopos estables de carbono (C), nitrógeno ( $N$ ) y azufre (S), realizados sobre muestras de restos humanos (cabello y uña) y sobre fibras de origen animal (camélidos). Las muestras proceden de un contexto funerario asociado con un asentamiento residencial agropastoril (sitio Punta de la Peña 9), localizado en la localidad de Antofagasta de la Sierra, Catamarca, Puna Meridional Argentina.

Los resultados son discutidos en el marco del conjunto de evidencias contextuales que se poseen para el sitio y de los modelos generales que se manejan, en relación con las estrategias de subsistencia, en el área de estudio y para el momento cronológico particular asociado con las muestras (ca. 1500 años AP).

Además de la incidencia en la dieta humana de productos de origen agrícola, como el maíz, se plantea que el análisis de isótopos en muestras animales propone una línea complementaria para el abordaje de problemáticas que trascienden la información paleodietaria de las poblaciones humanas. Entre éstas, destacamos aquellas vinculadas con el complejo y multivariado proceso de domesticación de camélidos en los andes meridionales y/o con las estrategias particulares desplegadas por la actividad pastoril.

\footnotetext{
Abstract

In this paper we present the results of carbon, nitrogen and sulfur stable isotope analysis performed on human (hair and nail) and animal (camelid fibers) samples. The sampled materials come from a funerary context associated to an agropastoralist settlement (Punta de la Peña 9), located in Antofagasta de la Sierra (Catamarca), in the Southern Puna of Argentina.

The results are discussed considering the whole contextual evidence recovered at the site as well as the available models about the subsistence strategies implemented by prehistoric populations of the area at ca. 1500 years B.P.

In addition to propositions about the incidence of agricultural products (e.g. maize) on the human diet, we propose that stable isotope analysis of animal samples constitutes a complementary and valuable line of inquiry about archaeological issues that go beyond strict paleodietary information. Among such issues are the complex and multivariate process of camelid domestication in the South Andean Area and/or with the specific strategies deployed by agropastoral activity at the regional level.
} 


\section{Introducción}

El objetivo del presente trabajo es dar a conocer los resultados obtenidos a partir del análisis de isótopos estables de carbono $(\mathrm{C})$, nitrógeno $(\mathrm{N})$ y azufre $(\mathrm{S})$. Los mismos han sido efectuados sobre muestras de restos humanos -cabello y uña- y sobre fibras de origen animal (camélidos), procedentes de un contexto funerario asociado con un asentamiento residencial agropastoril. Dicho contexto de inhumación ha sido recuperado en el espacio intramuros de un recinto que forma parte de un sitio ocupacional, localizado en la localidad de Antofagasta de la Sierra (ANS), en el NO de Catamarca.

El estudio de la dieta de las antiguas poblaciones, realizado a través de análisis como los aquí abordados, contribuye al conocimiento de numerosos aspectos de su organización, entre los que podemos destacar: a) características generales de la subsistencia; b) aspectos vinculados con el uso del espacio, rangos de interacción y/o movilidad de las comunidades; c) la existencia (o no) de diferencias nutricionales entre los miembros de una población; d) la detección de cambios en las estrategias o patrones de subsistencia, como por ejemplo el desarrollo o la intensificación de las prácticas agrícolas y/o la incorporación de nuevos alimentos a la dieta. Además, como se desprende de algunos resultados de esta investigación, este tipo de análisis puede proporcionar indicadores arqueológicos particulares para abordar el estudio de problemáticas vinculadas con el proceso de domesticación de camélidos y con las estrategias desplegadas en relación con la actividad pastoril, entre otros temas de interés para la arqueología regional.

\section{El contexto de recuperación de los materiales analizados}

La localidad de Antofagasta de la Sierra (ANS) se localiza en el ángulo NO de la provincia de Catamarca, en el denominado Sector Meridional de la Puna Argentina (Figura 1). Su rango altitudinal (3500 a $4200 \mathrm{msnm}$ ) y su biogeografía responden a las de un desierto de altura, constituyendo ANS una sucesión de oasis en el ambiente puneño, debido a la presencia de cursos de agua de régimen permanente, que originan vegas y ambientes aptos para el establecimiento y el desarrollo de poblaciones humanas.

El sitio Punta de la Peña 9 (en adelante PP9) se ubica en la cota altitudinal correspondiente a los Sectores Intermedios de esta localidad, emplazado sobre la margen Sur del Río Las Pitas, a una altitud de ca. $3600 \mathrm{msnm}$. Constituye una base residencial agrícola pastoril multicomponente, con una secuencia ocu pacional que se inicia hace aproximadamente 2000 años AP (López Campeny 2001a y 2001b) y se extiende hasta momentos prehispánicos tardíos e incluso históricos, evidenciando un uso recurrente y variable de los espacios para la realización de múltiples actividades (Cohen 2005; Babot et al. 2006; López Campeny 2006). Teniendo en cuenta la distribución espacial de la evidencia superficial y sus características de emplazamiento, en el sitio PP9 se han distinguido tres sectores: I, II y III (Babot et al. 2006).

El contexto funerario del que proceden las muestras analizadas ha sido recuperado en el espacio intramuros de la estructura 2 (E2), del sector III de PP9, cuyo espacio de ocupación se construyó aprovechando, a modo de muros, dos bloques de ignimbrita de gran tamaño, a los que se anexó un tercer cerramiento conformado por un pircado. Este recinto cuenta con un conjunto de cuatro dataciones radiocarbónicas para el total de seis niveles estratigráficos identificados durante las excavaciones. La secuencia documenta una serie de ocupaciones 


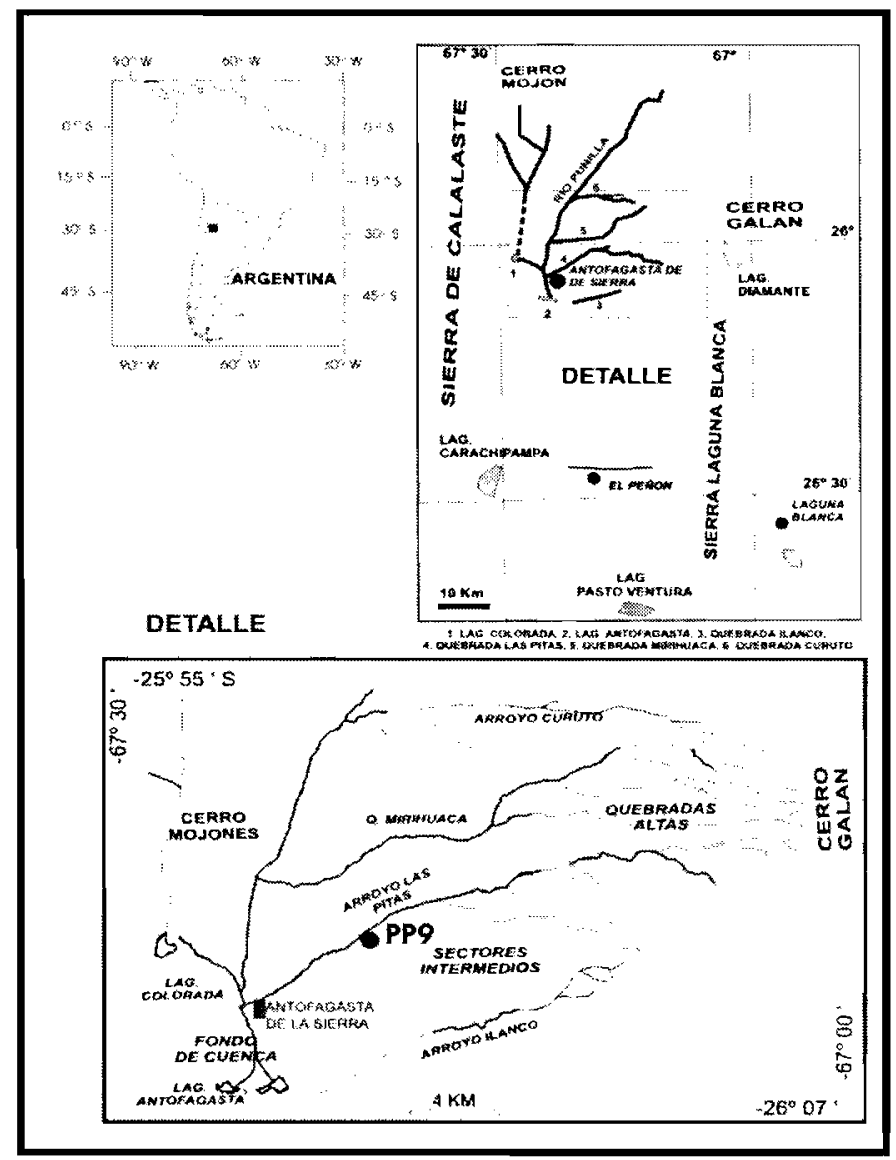

Figura 1. Ubicación geográfica del área de estudio: Antofagasta de la Sierra y el sitio PP9. Tomado de lópez Campeny et al. (2005: 13)

recurrentes de este locus residencial, entre ca. 2000 y 500 años AP, incluyendo varios eventos domésticos de residencia y consumo, el contexto funerario aludido y un evento de uso del espacio con fines productivos, como corral para el encierro de camélidos (López Campeny 2001a, 2001b, 2006).

Los materiales asociados al contexto funerario incluyen una elevada densidad de restos ecofactuales $^{2}$-la mayoría de origen no local- y un conjunto de tecnofacturas en soportes cerámico, vegetal, malacológico y fibra animal. Entre estas se incluyen: dos escudillas cerámicas, tres "paquetes" de cuero rellenos con vegetales (gramíneas y leñosas locales) ${ }^{3}$, un palo formatizado de madera de añagua (Adesmia horrida), un notable conjunto de piezas textiles y cordelería, cuentas de collar (malacológica y mineral) y un recipiente confeccionado en calabaza (Lagenaria siceraria), con trazos de pigmento rojo en su superficie (López Campeny 2000 y 2005).

Sin embargo, una característica notable de este contexto es el reducido conjunto de restos humanos que fueron recuperados. Este hecho, integrado a otra serie de elementos contextuales y estratigráficos que hemos discutido en contribuciones anteriores (López Campeny 2000, 2006), nos permitieron interpretar la existencia de un evento de reapertura 
de la tumba, el retiro de la mayor parte de los restos del individuo, la reorganización de los materiales remanentes y su posterior reentierro. Una muestra de semillas de chañar asociadas al contexto, proporcionó una datación radiocarbónica de $1460 \pm 40$ años $\mathrm{AP}$ (López Campeny 2000), fechado que asociamos con el evento original de depositación del contexto funerario. En relación con la reapertura de la tumba, sólo podemos afirmar que debió ocurrir en algún momento previo a la conformación del nivel estratigráfico superior, identificado como un sector de depositación secundaria de residuos (basurero). Al respecto, una muestra de carbón procedente de este nivel ha sido datada en $530 \pm 50$ años AP (López Campeny 2000), momento antes del cual debió producirse la reapertura de la tumba.

El estudio de la paleodieta. Principios generales y posibilidades del análisis isotópico.

La investigación arqueológica cuenta con una herramienta que permite conocer la dieta de un individuo, analizando la abundancia relativa de los isótopos estables de carbono (C), azufre (S) y nitrógeno (N) presentes en los componentes de sus tejidos orgánicos (Macko et al. 1999a y 1999b). El principio general en el que se basa este análisis consiste en que los constituyentes de los huesos y demás tejidos de los seres vivos proveen un registro promediado a largo plazo de la dieta del individuo, permitiendo relacionar cuantitativamente la composición química de los restos orgánicos con la composición química de la dieta. Esto se deriva del hecho de que los diferentes elementos químicos liberados durante el proceso de digestión de los alimentos se incorporan, durante todo el ciclo vital de los organismos, a las fracciones orgánicas e inorgánicas de sus huesos y demás tejidos (Lambert y Grupe 1993).

En el presente trabajo analizamos los isótopos estables de tres diferentes elementos presentes en las muestras arqueológicas orgánicas: carbono $(\mathrm{C})$, nitrógeno $(\mathrm{N})$ y azufre $(\mathrm{S})$. Las proporciones de isótopos estables pesados y livianos $\left({ }^{13} \mathrm{C}\right.$ y ${ }^{12} \mathrm{C},{ }^{15} \mathrm{~N}$ y ${ }^{14} \mathrm{~N},{ }^{34} \mathrm{~S}$ y $\left.{ }^{32} \mathrm{~S}\right)$ naturalmente presentes en un material, es decir, si no se ha aumentado experimentalmente la cantidad de un isótopo, se expresan como abundancia natural del isótopo pesado en la notación "delta" ( $\left.\delta^{13} \mathrm{C}, \delta^{15} \mathrm{~N}, \mathrm{y} \delta^{34} \mathrm{~S}\right)$.

Los valores de abundancia natural se calculan con la siguiente fórmula:

$\delta_{\text {muestra }}(\%$ o $)=\left(R_{\text {muestra }} / R_{\text {estándar }}-1\right) \times 1000(\%$ o $)$

Donde $\delta$ muestra representa $\delta^{15} \mathrm{~N}, \delta^{13} \mathrm{C}$ y $\delta^{34} \mathrm{~S}$, y R es el radio molar de los isótopos pesado y liviano (ej. ${ }^{13} \mathrm{C} /{ }^{12} \mathrm{C}$ ) de la muestra y del estándar (Hoefs 1997). Los valores de abundancia natural, o " para cada elemento tienen unidades de "per mil" (\%o ), que indican la abundancia relativa del isótopo pesado en la muestra, comparada con un material estándar que por definición tiene un valor de $0 \%$. Los estándares para el $\mathrm{N}, \mathrm{C}$ y $\mathrm{S}$ son el nitrógeno atmosférico $\left(\mathrm{N}_{2}\right)$, carbonato Pee Dee Belemnite (PDB) y la Trolita del Cañón del Diablo, respectivamente. Así, si un material contiene una mayor proporción de ${ }^{13} \mathrm{C},{ }^{15} \mathrm{~N}$ o ${ }^{34} \mathrm{~S}$ que el estándar, tendrá valores ' positivos, mientras que si contiente una menor proporción del isótopo pesado que el estándar, el valor'será negativo.

Sintetizaremos a continuación qué información sobre la dieta antigua brinda el análisis de la abundancia natural de los isótopos pesados $\left(\delta^{15} \mathrm{~N}, \delta^{13} \mathrm{C}\right.$ y $\left.\delta^{34} S\right)$ presentes en muestras humanas, animales y vegetales, para cada uno de estos elementos químicos. 
El dióxido de carbono $\left(\mathrm{CO}_{2}\right)$ de la atmósfera se incorpora al tejido de los vegetales terrestres y acuáticos a través del proceso de la fotosíntesis. Hay tres factores fundamentales que condicionan los valores de $\delta^{13} \mathrm{C}$ en las plantas: a) la proporción de ${ }^{13} \mathrm{C}$ presente en la fuente (sea ésta terrestre, acuática, o antropogénica), b) las vías fotosintéticas empleadas por las distintas especies y c) las condiciones ambientales (Lajtha y Marshall 1994; Barberena 2002).

En relación con la primera fuente de variabilidad, los vegetales terrestres incorporan el $\mathrm{CO}_{2}$ atmosférico, con valores que oscilan entre $-7 \%$ a $-8 \%$, mientras que el carbono disuelto en el agua tiene valores de $0 \%$ en el mar $y$, presenta amplias variaciones en aguas dulces carbonatos de distintos minerales o biogénico, con valores de entre $-5 \%$ y -20\%o- según su origen (Hoefs 1997). En segundo término, de acuerdo con su patrón fotosintético, las plantas terrestres se dividen en dos grupos principales ${ }^{4}$. Las plantas que fijan el $\mathrm{CO}_{2}$ con tres moléculas de carbono, llamadas plantas $\mathrm{C}_{3}$ (o pertenecientes al ciclo de Calvin-Benson) y las que lo hacen con una molécula de cuatro carbonos o plantas $\mathrm{C}_{4}$ (o pertenecientes al ciclo de HatchSlack). Las plantas $\mathrm{C}_{3}$ incluyen todos los árboles y la mayoría de los arbustos y pastos de áreas templadas y de estación fría. Las plantas $\mathrm{C}_{4}$ incluyen las hierbas de sabanas y de zonas tropicales cálidas y secas, así como algunos pocos arbustos de las familias Euphorbiaceae y Chenopodiaceae, y vegetales de gran valor nutritivo para las poblaciones humanas, como el maíz (Poaceae) (Downton 1975, citado en Barrientos 1999). Como consecuencia de estas diferencias en el metabolismo vinculadas con el ambiente, ambos tipos de plantas discriminan de manera diferente en contra del isótopo más pesado, estableciendo una relación bimodal cuyos valores no se superponen. El primer grupo de plantas $\left(C_{3}\right)$ posee proporciones bajas de incorporación del isótopo ${ }^{13} \mathrm{C}$ en sus tejidos relativo al isótopo ${ }^{12} \mathrm{C}\left(\delta^{13} \mathrm{C}-20 \%\right.$ a $-34 \%$, con un valor modal de $-27 \%$ o). El segundo grupo de plantas $\left(\mathrm{C}_{4}\right)$ posee proporciones de ${ }^{13} \mathrm{C}$ relativas a ${ }^{12} \mathrm{C}$ más altas que las de tipo $\mathrm{C}_{3}\left(\delta^{13} \mathrm{C}-9 \%\right.$ a $-16 \%$, con un valor modal de $-12 \%$ o $)$ conservando valores de $\delta^{13} \mathrm{C}$ más cercanos a los del $\mathrm{CO}_{2}$ atmosférico (Lajtha y Marshall 1994; Tieszen y Boutton 1989; Park y Epstein 1960, citado en Barrientos 1999). Finalmente, en relación con la variabilidad ambiental mencionada, podemos sintetizar que la proporción de $\mathrm{CO}_{2}$ en la atmósfera presenta diferencias en relación con la latitud, la altitud y la estacionalidad (factores que modifican la temperatura y la humedad en la atmósfera y en el suelo), desencadenando consecuentes variaciones isotópicas (Keeling et al. 1984; van der Merwe y Medina 1991, citado en Barberena 2002; Fernández y Panarello 1999-2001a).

La relevancia de estos procesos químicos para los estudios arqueológicos consiste en que las relaciones de isótopos estables de $C$ en los tejidos humanos tienen una correlación positiva con los valores isotópicos de su dieta. Por lo tanto, puede ser utilizada para establecer si los individuos consumieron una dieta basada principalmente en plantas $C_{3} y / o$ en herbívoros consumidores de plantas $C_{3^{\prime}}$ o si se trató de una dieta basada en plantas $C_{4} y / o$ animales principalmente consumidores de plantas $C_{4}$.

También la proporción de isótopos de $\mathrm{N}$ puede reflejar ciertos patrones de la dieta antigua. Principalmente, el nitrógeno se encuentra en forma de $\mathrm{N}_{2}$ en la atmósfera, que posee una composición isotópica homogénea con un valor aproximado de $\delta^{15} \mathrm{~N}$ de $0 \%$. Algunos tipos de plantas, como las legumbres y cianobacterias del suelo, fijan el $\mathrm{N}_{2}$ atmosférico que así entra a los suelos y plantas de los ecosistemas terrestres (Sprent 1995; Aranibar et al. 2003). La descomposición de la materia orgánica en los suelos produce un aumento del ${ }^{15} \mathrm{~N}$ entre un 5 y $10 \%$, a expensas de una pérdida relativa de ${ }^{14} \mathrm{~N}$ en compuestos gaseosos. Los vegetales asimilan el nitrógeno presente en los suelos, y en general muestran valores más bajos que éstos (Aranibar et al. 2004). El metabolismo animal resulta en un enriquecimiento paulatino, 
de entre 3 a $4 \%$ o de los valores de $\delta^{15} \mathrm{~N}$ de los alimentos, a medida que se asciende en cada nivel de la cadena trófica. Es decir que, los valores de ${ }^{15} \mathrm{~N}$ representan un indicador del nivel trófico del individuo analizado, pero también indican la presencia en la dieta de plantas fijadoras de nitrógeno, como por ejemplo las legumbres. Así, se observan valores de $\delta^{15} \mathrm{~N}$ de $7 \%$ para el nivel de herbívoros, ascendiendo este valor a $10 \%$ para individuos con una dieta carnívora u omnívora en el caso de especies de ambientes terrestres (Yesner et al. 1991; Macko et al. 1999a y 1999b).

Finalmente, la abundancia natural de los isótopos estables de $S\left({ }^{32} S y^{34} S\right)$ permite distinguir entre fuentes alimenticias de origen marino y terrestre (van der Merwe et al. 1993; Krouse 1989). Los sulfatos de los océanos tienen actualmente un valor de $\delta^{34} S$ relativamente constante de alrededor de 21\%o (Rees et al. 1978). Los aerosoles atmosféricos y la fauna marina, así como los animales que consumen productos marinos reflejan esos valores de $\delta^{34} S$, aunque menos enriquecidos en ${ }^{34} \mathrm{~S}$ (Krouse, 1989). Por ejemplo, muestras de cabellos humanos de poblaciones costeras de Chile (sitio Morro) presentaron valores de $\delta^{34} S$ de 14 a $16 \%$, mientras que los valores de otras muestras encontradas lejos de la costa (en el valle de Azapa) fueron menores a 10 \%o (Macko et al. 1999a). Estos resultados reflejan la contribución de los alimentos encontrados en los mismos sitios, ya que tejidos de peces y mariscos presentaron valores de $\delta^{34} S$ mayores a $15 \%$, mientras que maíz y tubérculos (jiquina) presentaron valores menores a $7 \%$. Durante la reducción bacteriana del sulfato, las enzimas bacterianas reaccionan preferentemente con el ${ }^{32} \mathrm{~S}$. Esta actividad microbiológica en ambientes terrestres resulta en valores de $\delta^{34} S$ terrestres menores a los del sulfato marino, lo que permite identificar el origen terrestre o marino de la dieta de poblaciones humanas o animales.

\section{Abordando el análisis de la paleodieta. Materiales y Métodos.}

Los análisis isotópicos pueden realizarse sobre distintos tipos de tejidos orgánicos, incluyendo cabello, uñas, dientes y huesos. En nuestro caso, se analizaron muestras de cabello y de uña humanas y de fibras de origen animal, materiales considerados altamente confiables para determinar la dieta en restos arqueológicos, ya que preservan la abundancia isotópica original (i.e. no están sujetos a profundas alteraciones diagenéticas) (Macko et al. 1999a). Se suma la ventaja de que, en el caso del pelo y uña, la velocidad de renovación es rápida y puede proporcionar información sobre la alimentación ingerida a lo largo de períodos de vida cortos, incluidos los inmediatamente anteriores a la muerte (Fernández y Panarello 1999-2001a).

Cabe aclarar que el MNI de la tumba (teniendo en cuenta el conjunto de restos óseos) es 1, con una edad estimada de entre 5 y 7 años para el individuo. La única evidencia presente en el contexto funerario asignable a un individuo adulto es la uña incluida en el análisis ( $\left.N^{\circ} 166\right)$, que resulta insuficiente para permitirnos inferir la presencia de un segundo cuerpo.

Todos los materiales analizados aquí han sido recuperados formando parte de este contexto funerario. El detalle de los mismos es el siguiente:

A) Muestras humanas:

1) Corresponde al $\mathrm{N}^{\circ} 177$. Se trata de un manojo de cabello recortado, es decir, que ninguno de los ejemplares conserva el sector correspondiente al bulbo capilar. 
2) Corresponde al $N^{\circ} 166$. La muestra analizada es una uña completa.

B) Muestras animales:

1) Corresponde al $\mathrm{N}^{\circ} 161$. Se trata de dos muestras de fibra de camélido (color claro) separadas de una de las tecnofacturas descriptas como "paquetes" de cuero rellenos con vegetales (Figura 2). Sobre la base del análisis microscópico de estas muestras pudo observarse: a) con relación a los grosores de las fibras, un alto porcentaje (65\%) correspondiente a fibras finas de hasta 26 micras, un muy bajo porcentaje (5\%) de fibras intermedias -de entre 31 a 66 micras- y la presencia de un $30 \%$ de pelos gruesos, todos cercanos a 70 micras; y b) que el porcentaje total de fibras que presentan médula (fragmentada en su mayoría) es de un $60 \%$, en tanto que los índices de medulación registrados (porción que ocupa la médula en relación al diámetro total de la fibras) son altos, con valores entre $0,7-0,8$. Estos resultados se compararon con los estándares publicados por Reigadas $(1995 ; 1996)$, permitiendo afirmar que los grosores de las fibras observados en estas muestras se corresponden con la tendencia bimodal, característica del bimanto presente en ejemplares de vicuña (Vicugna vicugna). Además de la variable grosor, los porcentajes e índices de medulación también apoyan la hipótesis de que las fibras de los "paquetes" corresponderían a un espécimen de vicuña (Figura 3).

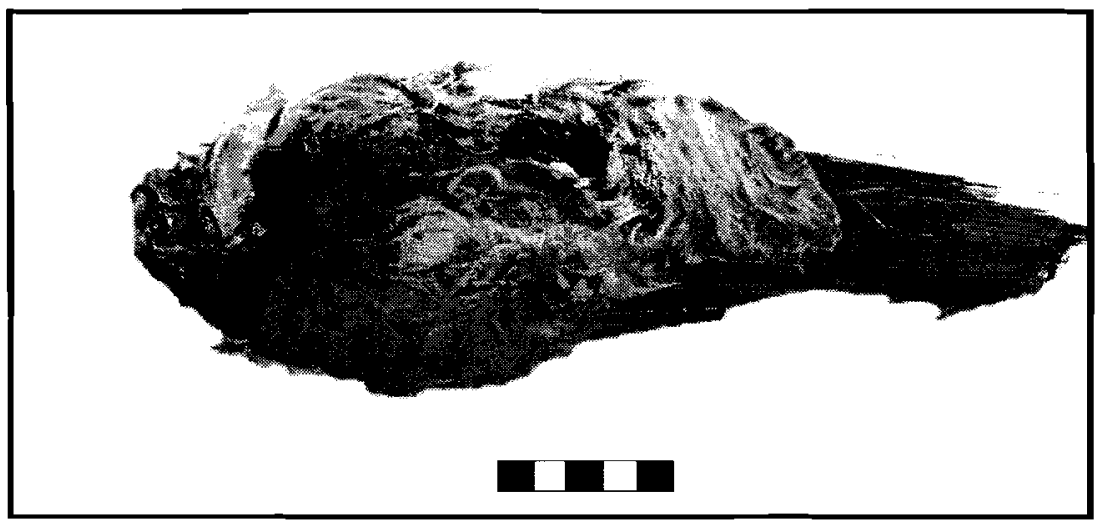

Figura 2. Artefacto descripto como "paquete" de cuero relleno con vegetales $\left(N^{\circ} 161\right)$ del que se extrajeron fibras para análisis isotópicos
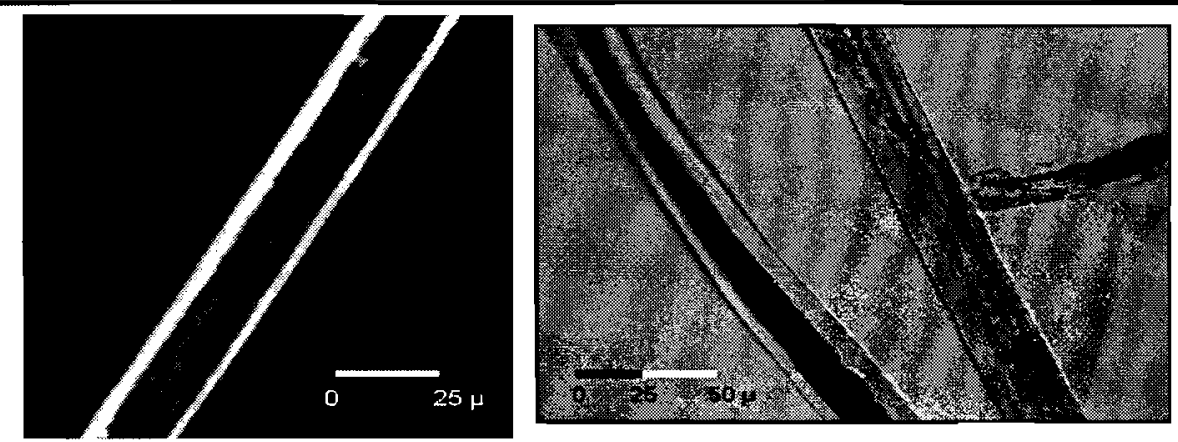

Fotografias tomadas en el microscopio a 400X: Muestra No 161

Figura 3. Fotografías microscópicas de la muestra de fibra procedente del artefacto $N^{\circ} 161$, determinada como vicuña (Vicugna vicugna) 
2) Corresponde al $N^{\circ} 196$. La muestra de fibra (color oscuro) se extrajo de un cordel con retorsión ( 8 cabos, torsionados de a pares con la fórmula sz4S), de casi $5 \mathrm{~m}$ de longitud y $11 \mathrm{~mm}$ de espesor (Figura 4). En cuanto al análisis microscópico de las fibras correspondientes a esta cuerda pudimos observar que, para la variable grosor, el $80 \%$ de las observaciones caen dentro de la frecuencia 50 - 55 micras. De acuerdo con los estándares citados (Reigadas op. cit), estos valores registrados corresponden al taxón llama (Lama glama) y no son coincidentes con los presentes en la lanilla y los pelos de vicuña y guanaco; en tanto que los grosores correspondientes a las fibras muy finas están ausentes o muy cercanos a grosores considerados para fibras intermedias. Por su parte, solo una observación arrojó valores coincidentes con pelos grucsos, pero también cercanos a los límites para ser tomados como medios. Es decir que, la muestra en general se caracteriza por fibras de grosores intermedios, correspondientes con un pelaje de una llama. Si a esto sumamos los altos porcentajes de fibras que presentan presencia de médula -continua y discontinua - y los bajos índices de medulación con valores entre 0,3 - 0,4, estos datos apoyan la determinación taxonómica planteada (Figura 5).

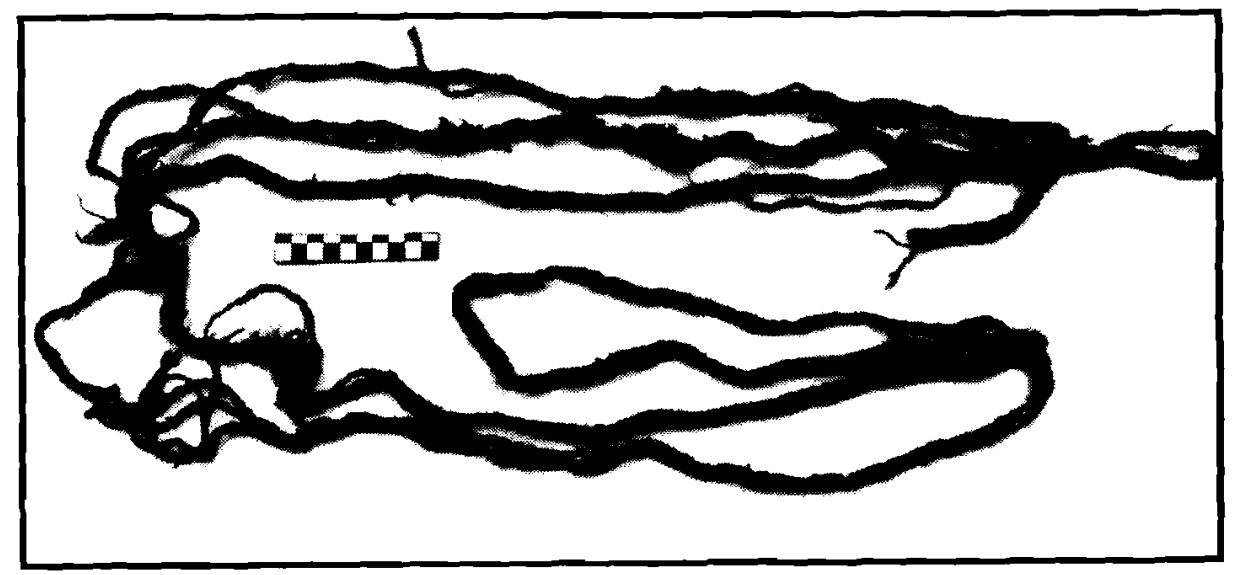

Figura 4. Extenso cordel con retorsión $\left(N^{\circ} 196\right)$ del que procede la segunda muestra de fibra animal sometida a análisis isotópico

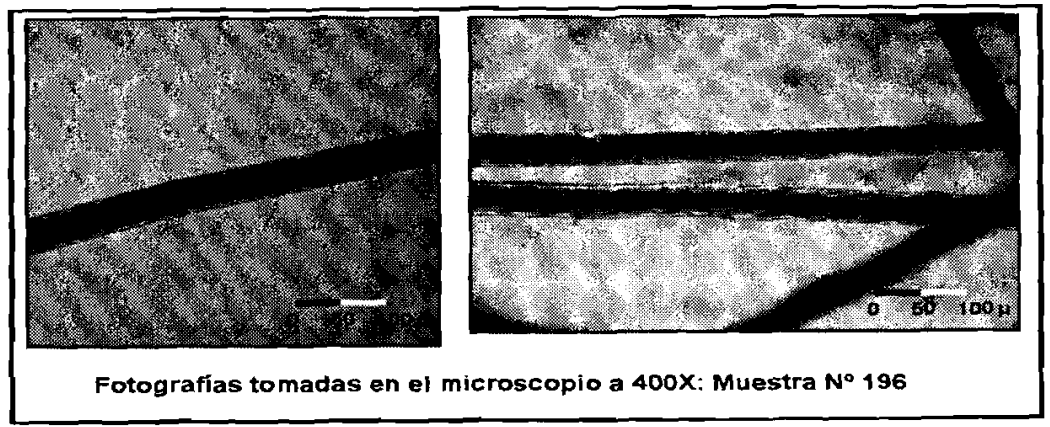

Figura 5. Fotografias microscópicas de la muestra de fibra procedente del artefacto $N^{\circ} 196$, determinada como llama (Lama glama) 


\begin{tabular}{|c|c|c|c|c|c|c|}
\hline MUESTRA & $6^{180 \%}$ & $46^{15} \mathrm{w} 6$ & $6^{32} \mathrm{~s} \%$ & $\begin{array}{l}\text { Fuente de C } \\
\text { predominante } \\
\text { (C, vs. C } 4)\end{array}$ & $\begin{array}{l}\text { Fuente de } \mathrm{H} \\
\text { predominante } \\
\text { vegetal vs. animal) }\end{array}$ & $\begin{array}{l}\text { Fuente de S } \\
\text { (terrestre vs. } \\
\text { marina) }\end{array}$ \\
\hline Maiz $(C)$ & -13.8 & & & & & \\
\hline Chañar (C) & 25.7 & & & & & \\
\hline Quinoa $\left(C_{3}\right)$ & -28.1 & & & & & \\
\hline Quinoa $\left(C_{3}\right)$ & -28.7 & & & & & \\
\hline 177 cahello & -13.2 & 11 & 4.9 & $\mathrm{C}_{4}$ & Productos animales & Terrestre \\
\hline $166-1$ uña & -13.6 & 9.2 & 6.9 & $\mathrm{C}_{4}$ & Productos animales & Terrestre \\
\hline 166.2 บทัด & -14.7 & 10.1 & & $\mathrm{C}_{4}$ & Productos animales & \\
\hline 1663 uña & -12.7 & 10.4 & & $c_{4}$ & Productos animales & \\
\hline 1664 uha & -13.1 & 10.1 & 8.1 & $C_{4}$ & Productos animales & Terrestre \\
\hline 1665 una & -11.8 & 10.0 & & $\mathrm{C}_{4}$ & Protluctos animales & \\
\hline 1666 una & .11 .3 & 10.5 & & $\mathrm{C}_{4}$ & Productos animales & \\
\hline 166.7 uha & -12.1 & 11.1 & 6.9 & $\mathrm{C}_{4}$ & Productos animales & Terrestre \\
\hline $\begin{array}{l}196-1 \\
\text { fibras llama }\end{array}$ & -18.8 & 4.7 & 9.1 & $C_{3} y C_{4}$ & $\begin{array}{c}\text { Vegetales fijadores } \\
\text { de nitrogeno }\end{array}$ & Terrestre \\
\hline $\begin{array}{l}1962 \\
\text { fibras llama }\end{array}$ & .19 .5 & 4.5 & & $C_{3}$ y $C_{4}$ & $\begin{array}{c}\text { Vegetales fijadores } \\
\text { de nitrogeno }\end{array}$ & \\
\hline $\begin{array}{l}1963 \\
\text { fibras llama }\end{array}$ & 19.7 & 4.6 & & $c_{3} y c_{4}$ & $\begin{array}{c}\text { Vejetales fijadotes } \\
\text { de nitrógeno }\end{array}$ & \\
\hline $\begin{array}{c}1964 \\
\text { fihras llama }\end{array}$ & -19.6 & 4.2 & 11.1 & $c_{3}$ y $C_{4}$ & $\begin{array}{c}\text { Vegetales fijadores } \\
\text { de nitrogeno }\end{array}$ & Terrestre \\
\hline $\begin{array}{l}196.5 \\
\text { fibras llama }\end{array}$ & -18.9 & 3.9 & & $\mathrm{C}_{3}$ y $\mathrm{C}_{4}$ & $\begin{array}{c}\text { Vegetales fijadores } \\
\text { de nitroyeno }\end{array}$ & \\
\hline $\begin{array}{l}196.6 \\
\text { fibras llama }\end{array}$ & -20.4 & 3.6 & & $C_{3} y_{-4}$ & $\begin{array}{c}\text { Vegetales fijadores } \\
\text { de nitrogeno }\end{array}$ & \\
\hline $\begin{array}{l}1967 \\
\text { fibras llama }\end{array}$ & -19.6 & 3.0 & 8.2 & $C_{3}$ y $C_{4}$ & $\begin{array}{c}\text { Vegetales fijadores } \\
\text { de nitrogeno }\end{array}$ & Terrestre \\
\hline $\begin{array}{c}1968 \\
\text { fibras llama }\end{array}$ & -19.6 & 3.2 & & $\mathrm{C}_{3} \times \mathrm{C}_{4}$ & $\begin{array}{c}\text { Vegetales fijadores } \\
\text { de nitrógeno }\end{array}$ & \\
\hline \multirow{2}{*}{$\begin{array}{l}161 \\
\text { fibras vicuña }\end{array}$} & -21.1 & 7.2 & & $\mathrm{C}_{3}$ & Vegetales & \\
\hline & 21.6 & 6.8 & & $\mathrm{C}_{3}$ & Vegetales & \\
\hline
\end{tabular}

Tabla 1. Abundancia natural de los isótopos de N, C y $S$ de las muestras procesadas, y principales fuentes de obtención inferidas.

Todas las muestras se trataron con una solución de etanol para remover residuos y restos de lípidos, que podrían alterar los valores de $\delta^{13} \mathrm{C}$. Las muestras de uña humana $\left(\mathrm{N}^{\circ} 166\right)$ y de fibra extraída de la cuerda $\left(\mathrm{N}^{\circ} 196\right)$ fueron analizadas en 7 y 8 porciones, respectivamente, para observar la variabilidad temporal de la dieta.

En las muestras de cabello y uña se analizó la abundancia natural de isótopos estables de carbono (C), nitrógeno (N) y azufre (S), utilizando un espectrómetro isotópico de masa "Micromass Optima" que tiene una precisión mayor que el 0.3 \% . Los análisis isotópicos se realizaron en el laboratorio isotópico del Departamento de Ciencias Ambientales de la Universidad de Virginia (USA).

Además, se analizaron los valores de $\delta^{13} \mathrm{C}$ de semillas de chañar (Geoffroea decorticans) asociados al mismo contexto funerario y granos de maíz (Zea mais) y quinoa (Chenopodium quinoa) recuperados en el sitio Punta de la Peña 4 (PP4), distante unos $200 \mathrm{~m}$ de PP9. Estas muestras vegetales se analizaron en la Universidad de Georgia (UGA), Center for Applied Isotope Studies (CAIS), como parte de los análisis de datación radiocarbónica, utilizando un espectrómetro de masa con acelerador (Culp 2005). 
Los resultados de abundancia isotópica natural se registran en relación a un estándar que, por definición, tiene un valor de $0 \%$, y se expresan en la notación "delta" ( ), como ya ha sido definido.

La proporción de alimentos derivados de plantas $\mathrm{C}_{3}$ y $\mathrm{C}_{4}$ se determinó usando la siguiente ecuación lineal: $\delta^{13} \mathrm{C}_{\text {muestra }}=\% \mathrm{C}_{3} \times \delta^{13} \mathrm{C}_{\mathrm{C} 3}+\% \mathrm{C}_{4} \times \delta^{13} \mathrm{C}_{\mathrm{C} 4}+f$ donde $\% \mathrm{C}_{3}$ y $\% \mathrm{C}_{4}$ son los porcentajes de plantas $\mathrm{C}_{3}$ y $\mathrm{C}_{4}$ presentes en la dieta del individuo de donde proviene la muestra, $\delta^{13} \mathrm{C}_{\mathrm{C}_{3}}$ y $\delta^{13} \mathrm{C}_{\mathrm{C} 4}$ son los valores de $\delta^{13} \mathrm{C}$ de plantas $\mathrm{C}_{3}$ (chañar y quinoa) y $\mathrm{C}_{4}$ (maíz) encontrados en la zona de estudio (Tabla 1). El parámetro " $f$ " es el fraccionamiento o enriquecimiento isotópico ocasionado por la asimilación del carbono en los tejidos de la muestra, que en el caso de cabellos y uñas es de alrededor de $1 \%$ por cada nivel trófico (Macko et al. 1999a, Tieszen et al. 1983). Tomando en cuenta que la evidencia arqueológica local indica consumo de carne animal, se consideró un valor de " $f$ " de $2 \%$ en el cálculo de la dieta humana, para incluir el efecto de la asimilación de carbono de los dos niveles

\begin{tabular}{|c|c|c|c|c|c|c|}
\hline MUESTRA & $\begin{array}{l}f-2 ; 0^{13} \mathrm{C}_{\mathrm{cs}} \\
\text { de guínoa }\end{array}$ & $\begin{array}{l}f=2.6^{13} C_{c 3} \\
\text { de chainar }\end{array}$ & $\begin{array}{l}f=1 ; \delta^{13} c_{c s} \\
\text { de quinoa }\end{array}$ & $\begin{array}{l}f-1,0^{13} \mathrm{C}_{\mathrm{cs}} \\
\text { de chaanar }\end{array}$ & $\begin{array}{l}f-4,0^{13} C_{C s} \\
\text { de quilioo }\end{array}$ & $\begin{array}{l}f=4: 0^{13} C_{c 3} \\
\text { de chañar }\end{array}$ \\
\hline 177 cabello & 90 & 88 & & & & \\
\hline 166-1 uña & 88 & 85 & & & & \\
\hline 1662 uña & 80 & 76 & & & & \\
\hline 1663 uha & 94 & 92 & & & & \\
\hline 1664 una & 91 & 89 & & & & \\
\hline $166-5$ uf́a & 100 & 100 & & & & \\
\hline 1666 uña & 100 & 100 & & & & \\
\hline 1667 uira & 98 & 97 & & & & \\
\hline $\begin{array}{c}196: 1 \\
\text { fibras Ilama } \\
\end{array}$ & & & $\underline{59}$ & 50 & $\underline{\mathbf{3 8}}$ & 24 \\
\hline \begin{tabular}{c|}
1962 \\
fibras llama
\end{tabular} & & & $\underline{54}$ & 44 & $\underline{34}$ & 18 \\
\hline $\begin{array}{c}196.3 \\
\text { fibras Ilama }\end{array}$ & & & $\underline{53}$ & 42 & $\underline{32}$ & 17 \\
\hline $\begin{array}{c}1964 \\
\text { fibras llama } \\
\end{array}$ & & & 53 & 43 & $\underline{33}$ & 18 \\
\hline \begin{tabular}{|c|}
1965 \\
fibras llama \\
\end{tabular} & & & $\underline{58}$ & 49 & $\underline{38}$ & 24 \\
\hline \begin{tabular}{|}
1966 \\
fibras llama \\
\end{tabular} & & & $\underline{48}$ & 36 & $\underline{27}$ & 11 \\
\hline $\begin{array}{r}1967 \\
\text { fibras llama }\end{array}$ & & & $\underline{53}$ & 43 & $\underline{33}$ & 18 \\
\hline $\begin{array}{c}196-8 \\
\text { fibras llama }\end{array}$ & & & $\underline{53}$ & 43 & $\underline{33}$ & 18 \\
\hline $\begin{array}{c}161 \text { fibras } \\
\text { vicuna }\end{array}$ & & & $\underline{43}$ & 30 & 23 & 5 \\
\hline $\begin{array}{c}161 \text { fibras } \\
\text { vicuna }\end{array}$ & & & $\underline{40}$ & 26 & 19 & 1 \\
\hline
\end{tabular}

Tabla 2. Porcentajes de plantas $\mathrm{C} 4$ consumidas por humanos y camélidos calculadas con distintos valores de $\delta{ }^{13} \mathrm{CC}_{3}$ (correspondientes a quinoa o chañar de la Tabla 1) y " $f^{11}$ (1\%o por nivel trófico, como es comúnmente calculado, y además $4 \%$ parn cantélidos, según los valores reportados en Fernández y Panarello, 1999-2001a). Resaltamos en subrayado los valores que consideramos más apropindos para nuestro estudio. No se calcularon los porcentajes de la dieta humana con $f=4 \%$, ya que la existencia de ese fraccionamiento ha sido propuesto para pelos de camélidos, que no son consumidos por los humanos.

Los músculos animales, que son los que probablemente se consumian, muestran comúnmente una diferencia de $1 \%$ con los vegetales de su dieta. 
tróficos: consumo de plantas por los hebívoros y consumo de herbívoros por los humanos. Para calcular la dieta animal, se consideró un valor de " $f$ " de $1 \%$. Los cálculos de la proporción de vegetales $C_{3}$ y $C_{4}$ pueden variar según se consideren distintos valores de $\delta^{13} \mathrm{C}$ de ambos tipos de plantas, en éste caso, muestras de plantas $\mathrm{C}_{3}$ : quinoa y chañar. Otra fuente de error mencionada (Fernández y Panarello 1999-2001a) está relacionada al valor de " $f$ ", que, según estudios en la Puna de Jujuy, podría ser mayor que 1 \%o para pelo de camélidos, aunque no se conocen los mecanismos responsables. Con el objetivo de indicar el efecto de estas fuentes de error en las conclusiones derivadas de nuestros resultados, también calculamos los porcentajes de plantas $C_{3}$ y $C_{4}$ en la dieta utilizando distintos valores probables de los parámetros " $f^{\prime}$ y $\delta^{13} \mathrm{C}_{\mathrm{C} 3}$ para la zona y material de estudio (Tabla 2).

\section{Documentando la dieta antigua. Los resultados obtenidos.}

Las cuatro muestras procesadas produjeron los resultados que sintetizamos en la Tabla 1 y representamos en las Figuras 6,7 y 8.

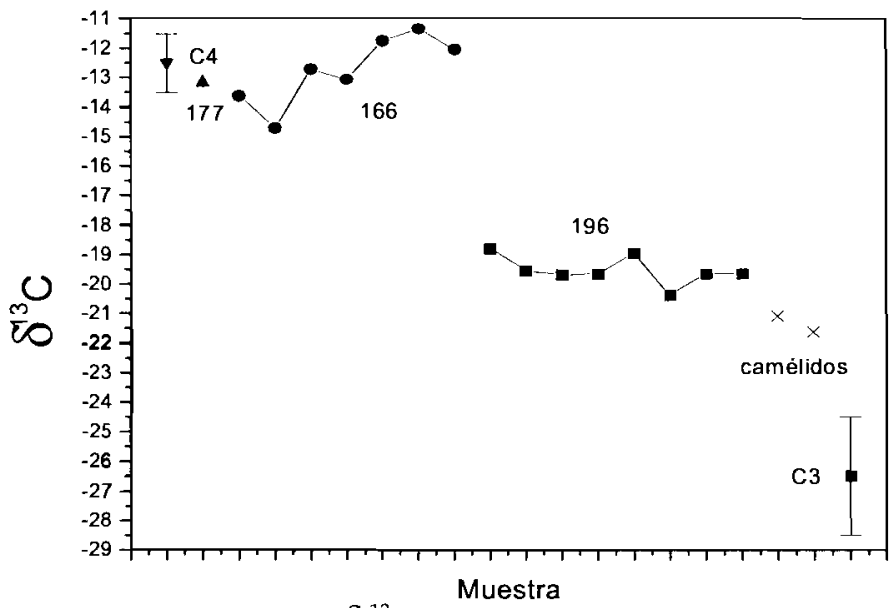

Figura 6. Proporción de $\delta{ }^{13} \mathrm{C} \%$ en las muestras humanas y animales

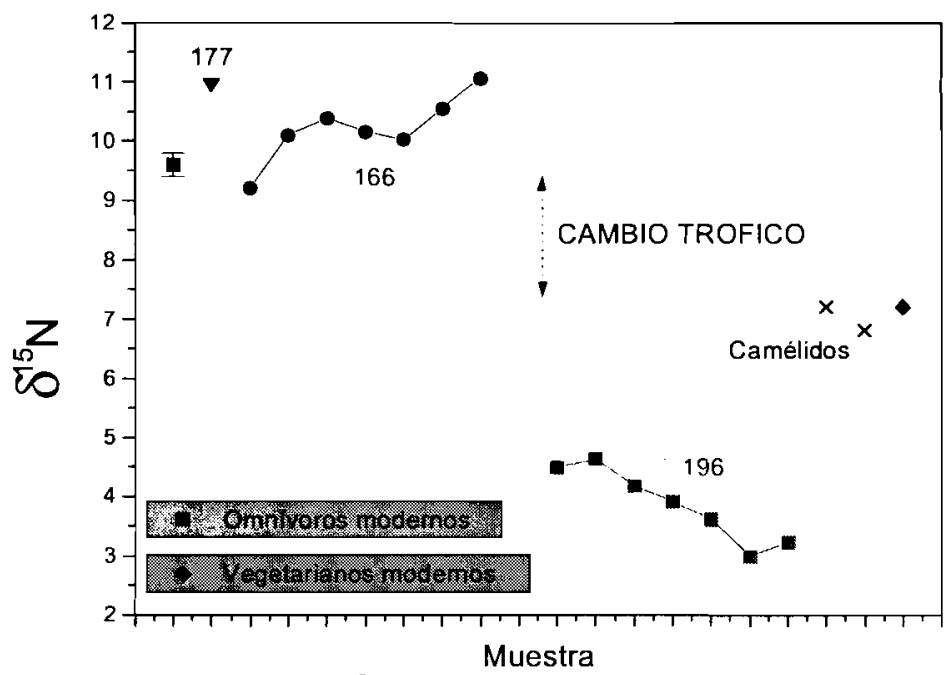

Figura 7. Proporción de $\delta{ }^{15} \mathrm{~N} \%$ en las muestras humanas y animales 
A continuación, se exponen las principales observaciones que se desprenden de los valores de abundancia isotópica natural obtenidos para cada elemento.

Los granos de maíz y semillas de chañar analizados (Tabla 1) presentaron valores de $\delta^{13} \mathrm{C}$ coherentes con los valores reportados en ambientes similares al área de estudio (Fernández y Panarello, 1999 y 2001a). Las semillas de chañar tienen valores de $\delta^{13} \mathrm{C}$ mayores que las de quinoa (más de $2 \%$ ), indicando una mayor utilización de ${ }^{13} \mathrm{C}$, comúnmente asociada a una mayor eficiencia de uso del agua, mediante un cierre de los estomas para evitar la transpiración (Farquhar et al. 1989). Esta diferencia isotópica entre ambos tipos de plantas coincide con un origen geográfico distinto para cada una de las dos muestras. Si se asume que los granos de quinoa, chañar y maíz son representativos de las plantas consumidas, se puede calcular la proporción de carbono en la muestra humana que proviene de plantas $\mathrm{C}_{3}$ $\mathrm{y} \mathrm{C}_{4}$. En la Tabla 2 indicamos los porcentajes de plantas $\mathrm{C}_{4}$ calculados con el valor de $\delta^{13} \mathrm{C}$ de ambas plantas, para indicar el rango de valores que se obtendrían si se hubieran consumido los dos tipos de plantas $\mathrm{C}_{3}$. El fraccionamiento isotópico, es decir el enriquecimiento en ${ }^{13} \mathrm{C}$ ocasionado por la asimilación de carbono en cada nivel trófico, se consideró ser de $1 \%$ (Macko et al. 1999a; Tieszen et al. 1983). Dado que la dieta humana puede contener carbono de origen animal o vegetal, se consideró un fraccionamiento total de $2 \%$, para incluir el efecto de la asimilación de carbono por los hebívoros y humanos. Así, el $90 \%$ del carbono de la muestra de cabello humano $\left(\mathrm{N}^{\circ} 177\right)$ y del 80 al 100 del de la uña humana $\left(N^{\circ} 166\right)$ analizados proviene de plantas $\mathrm{C}_{4}$ (Tabla 2). Los distintos valores de $\delta^{13} \mathrm{C}$ en la uña humana reflejan la variabilidad temporal de la dieta del mismo individuo durante el período de crecimiento de la uña, indicando un mayor consumo de carbono proveniente de plantas $\mathrm{C}_{3}$ en un extremo (de 12 a $20 \%$ ) y un consumo casi exclusivo de carbono proveniente de plantas $\mathrm{C}_{4}$ en el otro (de 98 a 100\%). Basándonos en poblaciones humanas actuales, estimamos que la escala temporal que la muestra de uña representa es menor a 1 año, por lo que las variaciones isotópicas podrían estar asociadas a variaciones estacionales en la disponibilidad de alimentos, aunque el patrón no resulta fácilmente interpretable. Los valores de $\delta^{13} \mathrm{C}$ en ambas muestras humanas indican que el carbono de la dieta proviene principalmente de plantas $\mathrm{C}_{4}$, ya sea mediante el consumo directo de cultígenos como el maíz, o mediante el consumo de animales que se alimentaban de plantas con metabolismo $\mathrm{C}_{4}$. Este resultado es coherente con las evidencias contextuales -arqueobotánicas y tecnológicas- que se poseen para el sitio PP9 y los modelos generales que se manejan, en relación con las estrategias de

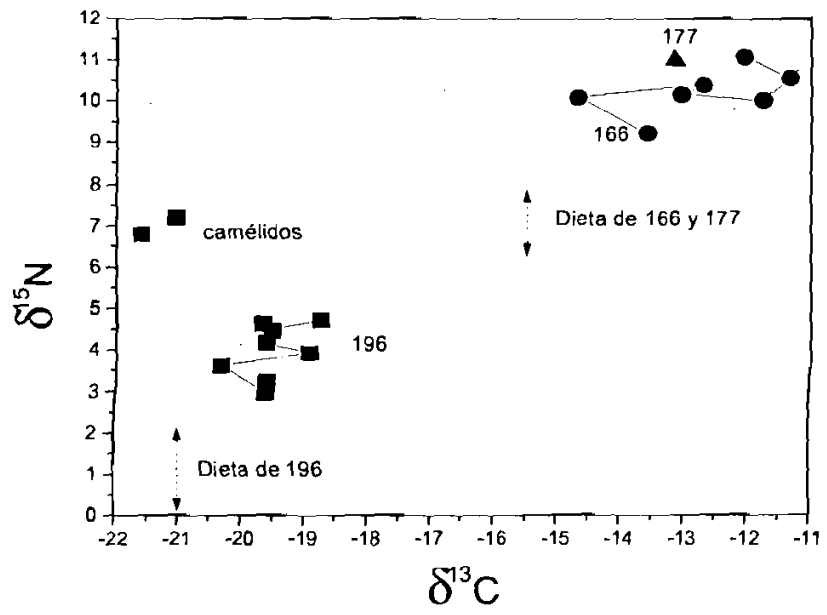

Figura 8. Proporción de $\delta{ }^{15} \mathrm{~N} \%$ y de $\delta^{13} \mathrm{C} \%$ en las muestras humanas y animales. 
subsistencia -una base agrícola pastoril con un importante componente de caza y recolecciónpara este período (ca. 1500 años AP), en el área de estudio (cf. Olivera 1992, 2006; López Campeny 2001a; Cohen 2005; Babot et al. 2006).

Por su parte, los valores de $\delta^{13} \mathrm{C}$ en las muestras de fibras de camélidos, indican que estos ungulados consumían una mayor proporción de plantas con metabolismo $\mathrm{C}_{3}$ que los humanos. De todos modos, las fibras identificadas como correspondientes a llama ( $\left.{ }^{\circ} 196\right)$ indican una menor proporción de plantas $\mathrm{C}_{3}$ en la dieta que las fibras de vicuña (Tabla 2). Generalmente, las pasturas naturales de este ecosistema, los pastos de áreas frías, al igual que en zonas altas, tienen este metabolismo $C_{3}$ (Rodríguez 2006). Sin embargo, camélidos puneños provenientes de zonas más bajas que $3600 \mathrm{msnm}$ presentan valores de $\delta^{13} \mathrm{C}$ de colágeno correspondientes a una dieta con una mayor abundancia de plantas $\mathrm{C}_{4}$ las que son más comunes a menor altitud (Fernandez y Panarello 1999-2001b).

Basándonos en sólo un elemento (carbono), no es posible determinar si el carbono en las muestras humanas proveniente de plantas $C_{4}$ resultó del consumo directo de maíz o de animales alimentados de pastos $C_{4}$. Sin embargo, los valores de $\delta^{13} \mathrm{C}$ humanos y animales indican la presencia inequívoca de plantas $C_{4}$ en la dieta, ya que el consumo exclusivo de carne de los camélidos analizados no podría haber originado los valores de $\delta^{13} \mathrm{C}$ humanos observados. Incluso si el fraccionamiento isotópico con respecto a la dieta es mayor en camélidos, como ha sido sugerido por Fernandez y Panarello (1999-2001a), los resultados siguen indicando una dieta predominante en plantas $C_{3}$ para camélidos (Tabla 2), y en consequencia, la necesidad de incluir el consumo de plantas $C_{4}$ para explicar los valores de $\delta^{13} \mathrm{C}$ observados en humanos. La única planta $\mathrm{C}_{4}$ presente en los sitios arqueológicos es el maíz, ya que la quinoa encontrada en el sitio PP4 presenta una clara abundancia relativa de ${ }^{13} \mathrm{C}$ correspondiente al metabolismo $\mathrm{C}_{3}$, al igual que otras muestras de quinoa encontradas en Mendoza (Fernández et al. 1999, citado en Novellino y Guichón 1999). Para dilucidar si en la dieta predominaban los vegetales o los animales, también utilizamos otra herramienta isotópica: la abundancia natural de ${ }^{15} \mathrm{~N}$.

Los valores de $\delta^{15} \mathrm{~N}$ en las muestras humanas, indican que la dieta de estos individuos tenía un importante componente de origen animal, que podría haber sido obtenido de la carne, los huevos o la leche. Comparando con valores de poblaciones humanas actuales, se trataría de una dieta omnívora, de un nivel claramente más alto que el de los valores proporcionados por el análisis de la fibra de camélido extraída del "paquete" $\mathrm{N}^{\circ} 161$. Esta última muestra coincide claramente con la diferencia isotópica de $3 \%$ comúnmente observada entre dos niveles tróficos distintos: herbívoros $(7 \%$ ) a carnívoros $u$ omnívoros (10\%o) (Macko et al. 1999a y 1999b).

Por otra parte, la muestra de la cuerda ( $\left.{ }^{\circ} 196\right)$ presenta resultados diferentes, ya que los valores de $\delta^{15} \mathrm{~N}$ son menores que los de los otros herbívoros. Estos valores indicarían que el individuo en cuestión tuvo una dieta vegetariana, pero que las plantas incluidas en su dieta eran diferentes a las consumidas por los portadores de las fibras de los envoltorios de cuero. El $\delta^{15} \mathrm{~N}$ de la dieta de este individuo tenía valores de 0 a $1.7 \%$, característicos de plantas fijadoras de nitrógeno como algunas legumbres (Figura 7). Ejemplos de legumbres que podrían haber estado incluidas en su dieta, y que fueron encontradas en el sitio, son endocarpos de algarrobo (Prosopis sp.), semillas de añagua (Adesmia sp.), semillas de chañar (Geoffroea decorticans) y cotiledones de poroto (Phaseolus sp.) (Figura 7 y Figura 8). 
Con respecto a la variabilidad temporal, la muestra $N^{\circ} 166$ (uña humana) muestra una disminución de $2 \%$ en los valores de $\delta^{15} \mathrm{~N}$, desde el final al principio de los cortes sucesivos de la muestra. También la muestra $N^{\circ} 196$ (cuerda) varía de 3 a 4,7\% , indicando una variación temporal en el consumo de distintos tipos de vegetales fijadores y no fijadores de nitrógeno (i.e. legumbres y no legumbres).

Por último, los isótopos de azufre de las muestras analizadas indican claramente una dieta de origen terrestre. Este resultado es coherente con la ubicación continental del área de estudio, pero es relevante para descartar contundentemente la posibilidad de un enriquecimiento de $\delta^{13} \mathrm{C}$ producto del consumo de ciertos alimentos marinos; aún cuando existen evidencias arqueológicas de fuertes interacciones entre los habitantes de ambas vertientes andinas.

\section{Analizando los patrones paleodietarios obtenidos. Discusión de los resultados.}

La observación de las figuras 6,7 y 8 permite notar que las muestras de cabello y uña humanas se separan claramente de las muestras de fibras animales, tanto en lo que respecta a los valores de $\delta^{33} \mathrm{C} \%$, como de $\delta^{15} \mathrm{~N} \%$. En el caso de los isótopos estables de carbono, esta situación se traduce, para las muestras humanas, en una dieta con un componente importante de plantas $C_{4}$ (entre el 80 y el $100 \%$ ), mientras que los valores de las fibras animales representan una dieta con un mayor contenido de vegetales $\mathrm{C}_{3}$ (ver la variación de valores calculados en la Tabla 2). Estos datos son coherentes, por un lado, con las expectativas de una dieta humana diferenciada de una dieta animal y, por otra parte, con las hipótesis manejadas en relación con las estrategias de su bsistencia que, para este momento de ocupación (ca. 1500 años AP), habrían sido desplegadas por los habitantes de PP9. En relación con esto último, en un ambiente como el analizado, donde los vegetales $C_{3}$ dominan el paisaje (Rodríguez 2006), es posible plantear que la elevada proporción de plantas $\mathrm{C}_{4}$ en la dieta humana estaría vinculada con el consumo de cultígenos tales como el maíz. En cuanto a las muestras animales, el predominio de plantas $\mathrm{C}_{3}$ en la dieta es coherente con el tipo de vegetales predominantes en el ambiente (Rodríguez 2006).

Si observamos los resultados obtenidos para los valores de $\delta^{15} \mathrm{~N}$, notamos también una clara diferenciación entre las muestras humanas y las animales. Las primeras corresponderían a una dieta de tipo omnivora, con un importante aporte de productos de origen animal, mientras que las segundas exhiben valores claramente correspondientes a una dieta vegetariana.

Los resultados de $\delta{ }^{13} \mathrm{C}$ y $\delta{ }^{15} \mathrm{~N}$ parecen contradecirse, ya que los primeros indican un predominio de vegetales $\mathrm{C}_{4}$ en la dieta y los segundos indican una dieta omnivora, con un componente importante de productos animales. Sin embargo, distintos alimentos difieren en las concentraciones de nitrógeno y carbono que aportan a la dieta. Por ejemplo, la carne de camélido proporciona una mayor cantidad de proteínas (ricas en N) que el maíz, el cual aporta principalmente carbohidratos. Los resultados de las muestras humanas indican que el nitrógeno asimilado es de origen animal, mientras que el carbono asimilado proviene de plantas $\mathrm{C}_{4}$. Dado que los camélidos analizados consumían una menor proporción de plantas $\mathrm{C}_{4}$ que los humanos, el consumo directo de plantas $\mathrm{C}_{4}$ por los humanos puede explicar sus valores de $\delta^{13} \mathrm{C}$. Alternativamente, los humanos podrían haberse alimentado de camélidos $u$ otros animales provenientes de zonas bajas, donde las plantas $C_{4}$ son más abundantes (Fernández y Panarello 1999-2001b). 
Otro punto que nos parece interesante destacar, es que la muestra obtenida de la cuerda ( $\left.\mathrm{N}^{\mathrm{0}} 1 \mathrm{196}\right)$, presenta valores diferentes a los proporcionados por las fibras del "paquete" de cuero, tanto en el caso de la composición isotópica de carbono como de nitrógeno. Consideramos que estas diferencias isotópicas observadas entre ambas muestras estarían dadas por la existencia de una alimentación vegetal diferente en cada caso, ya sea que se trate de especies silvestres o domesticadas. El porcentaje de especies $\mathrm{C}_{4}$ calculado para camélidos varía considerablemente con el valor del fraccionamiento isotópico utilizado (Tabla 2). Por lo tanto, sería importante ampliar los estudios de fracionamiento isotópico en camélidos bajo condiciones controladas (ej. con una dieta conocida), para obtener un valor de fraccionamiento isotópico más preciso y así reducir los errores asociados a este parámetro.

\section{Paleodieta y algo más. Comentarios finales y perspectivas futuras.}

Podemos plantear que el análisis comparativo de los valores isotópicos de muestras animales y vegetales propone una interesante línea para el abordaje de problemáticas que trascienden la información paleodietaria de las poblaciones humanas. Nos referimos a la posibilidad de abordar estudios vinculados con el complejo y multivariado proceso de domesticación de camélidos en los andes meridionales y de analizar aspectos particulares vinculados con el manejo pastoril y la alimentación del rebaño, a partir de la utilización de indicadores isotópicos.

Consideramos que los datos isotópicos sólo cobran verdadero significado en un análisis de tipo comparativo, por lo que resulta de suma relevancia la ampliación de la muestra de análisis aquí presentada, así como la recopilación de información correspondiente a los valores isotópicos de diferentes vegetales y animales presentes actualmente en el área de estudio.

Respecto del primer punto señalado, creemos relevante ampliar la base comparativa, mediante el análisis de muestras humanas que cubran un espectro cronológico amplio, lo que permitiría detectar si existieron cambios, a lo largo del período involucrado, en la composición de la dieta. Esto permitiría evaluar, por ejemplo, el rol de la agricultura y la introducción de cultígenos en este sector del desierto de altura y la incidencia del proceso de domesticación de camélidos en la dieta de estas poblaciones. Al respecto, señalamos que existen datos isotópicos disponibles para muestras humanas con una cronología más temprana que la del contexto funerario de PP9 (Macko et al. 2001). Dichas muestras han sido tomadas del cabello de un párvulo que formaba parte de un fardo funerario, recuperado en el sitio Punta de la Peña 11 (PP11), también ubicado en la localidad arqueológica de Punta de la Peña. El hallazgo ha proporcionado una datación de $3370 \pm 164$ años AP (Aschero et al. 1999). En él, los valores de $\delta^{13} \mathrm{C}$ muestran una menor proporción (de 64 a $70 \%$ según se considere la quinoa o el chañar como representativos de las plantas $C_{3}$ consumidas) de plantas $\mathrm{C}_{4}$ en la dieta (Macko et al. 2001), en relación con los porcentajes proporcionados por las muestras orgánicas de la tumba de PP9 (III) (80 a 100\%). Estos porcentajes nos permiten notar, en este lapso de aproximadamente 1900 años, un notable incremento en la proporción de los vegetales $C_{4}$ que están presentes en la dieta humana de los individuos de ANS.

Por otra parte en otros sitios de la microregión donde la recuperación de restos vegetales es de muy baja frecuencia debido a problemas de conservación (cf. Olivera 1992) el análisis isotópico de restos óseos puede brindar información sobre la importancia relativa de los 
diferentes tipos de plantas consumidas. De todas maneras, aún en el caso de sitios que presentan buenas condiciones de conservación de restos orgánicos, es importante tener presente que la sola presencia de restos botánicos o faunísticos no nos permite estimar, de manera directa, su importancia relativa en la dieta de los individuos. Los análisis isotópicos, en cambio, permiten identificar estas tendencias en la composición de la dieta y estimar las proporciones relativas de los principales componentes.

En síntesis, quisiéramos concluir remarcando que la información isotópica no puede ni debe reemplazar al análisis de los restos ecofactuales, sino que su relevancia radica en que permite complementar o ampliar la información de la subsistencia procedente tanto de los restos arqueobotánicos, como arqueofaunísticos (López Campeny et al. 2005).

Solamente un análisis integrado de toda la evidencia arqueológica contextual nos puede proporcionar un panorama más confiable, aunque difícilmente definitivo, sobre el conjunto de las especies vegetales y animales que integraban la dieta de las antiguas poblaciones del área de estudio.

\section{Agradecimientos:}

A Gustavo Barrientos y un segundo evaluador anónimo, por sus oportunas sugerencias para mejorar una versión anterior de este trabajo; aunque los autores somos absolutos responsables del contenido final del mismo. Las investigaciones en Antofagasta de la Sierra fueron desarrolladas en el marco de Proyectos dirigidos por el Lic. Carlos Aschero y financiados por el CONICET y el CIUNT.

\section{Notas}

1. Este artículo es una versión revisada y actualizada de una ponencia originalmente presentada en el XIV CNAA en la ciudad de Rosario, en el mes de septiembre del año 2001.

2. Se recuperaron carozos de chañar (Geoffroea decorticans), endocarpos de algarrobo (Prosopis sp.), granos de maíz (Zea mays), cotiledones de poroto (Phaseolus sp.) y una valva completa de un caracol marino (Familia Fissurellidae). La identificación de las especies vegetales fue realizada por la Dra. M. Fernanda Rodríguez y el Profesor Emilio Ulibarri, Instituto de Botánica Darwinion, Buenos Aires. La identificación malacológica ha sido efectuada por las Zoólogas F. Drahg y Gabriela Cuezzo, Facultad de Ciencias Naturales e IML, UNT.

3. Correspondientes a ejemplares de gramíneas identificadas como Deyeuxia deserticola, Festuca orthophylla, Stipa vaginata (Familia Poaceae) y tallos de Atriplex inabricata (Familia Chenopodiacea).

4. Existe un tercer grupo de plantas, denominadas CAM (i.e. con el metabolismo ácido de las crasuláceas) que incluyen a las suculentas de zonas áridas como los cactus y a las orquídeas en las florestas tropicales húmedas. Éstas cubren todo el espectro de variación isotópica de las $\mathrm{C}_{3}$ y $\mathrm{C}_{4}$, incluyendo también tasas intermedias, ya que utilizan alternativamente ambos tipos de fotosíntesis de acuerdo con las condiciones ambientales (Barberena 2002).

\section{Bibliografía citada}

Aranibar, J. N., I. C. Anderson, S. Ringrose y S. A. Macko 2003. Importance of nitrogen fixation in soil crusts of southern African arid ecosystems: acetylene reduction and stable isotope studies. Journal of Arid Environments 54, 345-358. 
Aranibar, J. N., L. Otter, S. A. Macko, C. J. W. Feral, H. E. Epstein, P. R. Dowty, F. Eckardt, H. H. Shugart y R. J. Swap

2004. Nitrogen cycling in the soil-plant system along a precipitation gradient in the Kalahari sands. Global Change Biology 10: 359-373.

Aschero, C. A.; R. Zurita; M. G. Colaneri y A. Toselli.

1999. El bebé de la Peña. En Actas del XIII Congreso Nacional de Arqueología Argentina, Tomo II: 329-338, Córdoba.

Babot, M. del P., C. A. Aschero, S. Hocsman, C. Haros, L. González Baroni y S. V. Urquiza 2006. Ocupaciones agropastoriles en los Sectores Intermedios de Antofagasta de la Sierra (Catamarca): Un análisis desde Punta de la Peña 9.I. Comechingonia 9: 57-75.

Barberena, R.

2002. Los limites del mar. Isótopos estables en Patagonia meridional. Colección. Tesis de Licenciatura Sociedad Argentina de Antropología. Buenos Aires.

Barrientos, G.

1999. Composición isotópica $\left({ }^{13} \mathrm{C}\right)$ de muestras de restos óseos humanos del sitio Arroyo Seco 2 (Pcia. de Bs As): inferencias paleodietarias. Relaciones XXIV: 81-94.

Cohen, M. L.

2005. Entre guano y arena... Ocupaciones recurrentes: Un caso de estudio en el sitio Punta de la Peña 9 III, Antofagasta de la Sierra, Catamarca. Trabajo Final de Carrera de Arqueología. Inédito, Facultad de Ciencias Naturales e Institu to Miguel Lillo. Universidad Nacional de Tucumán.

Culp, R.

2005 Radiocarbon Analysis Report. Center for Applied Isotope Studies (CAIS), University of Georgia (informe inédito en posesión de los autores)

Farquhar G. D., K. T. Hubick, A. G. Condon y R. A. Richards

1989. Carbon Isotope Fractionation and Plant Water-Use Efficiency. En W. Rundel, J. R. Ehleringer y K. A. Nagy (Eds.) Stable Isotopes in Ecological Research, Springer-Verlag, New York

Fernández, J. y H. Panarello

1999-2001a. Los isótopos estables del carbono en pelo de animales silvestres de ambientes altiplánicos de Argentina. Xama 12-14: 61-69.

Fernández, J. y H. Panarello 1999-2001b. Isótopos del carbono en la dieta de herbívoros y carnívoros de los andes jujeños. Xama 12-14: 71-85.

Hoefs, J.

1997. Stable Isotope Geochemistry. Springer-Verlag, Berlin.

Keeling, C. D., A. F. Carter y W. G. Mook

1984. Seasonal, latitudinal and secular variations in the abundance and isotopic ratio of 
atmospheric carbon dioxide II. Results from oceanographic cruises in the Tropical Pacific Ocean. Journal of Geophysical Research 89: 4615-4628.

Krouse, H. R.

1989. Sulfur Isotope Studies of the Pedosphere and Biosphere. En W. Rundel, J. R. Ehleringer y K. A. Nagy (Eds.) Stable Isotopes in Ecological Research. Springer-Verlag, New York.

Lambert, J. y G. Grupe (Eds.)

1993. Prehistoric Human Bone. Archaeology at the Molecular level. Springer Verlag, Berlín Heidelberg - New York.

Lajtha K. y J. D. Marshall

1994. Sources of variation in the stable isotopic composition of plants. En K. Lajtha y R. H. Michener (Eds.) Stable Isotopes in Ecology and Environmental Sciences. Blackwell Scientific Publications, Oxford.

López Campeny, S. M. L.

2000. Tecnología, Iconografía y Ritual funerario. Tres dimensiones de análisis de los textiles formativos del Sitio Punta de la Peña 9 (Antofagasta de la Sierra, Argentina). Estudios Atacameños 20: 29-65.

2001a. Actividades domésticas y organización del espacio intrasitio. El sitio Punta de la Peña 9. Antofagasta de la Sierra (Prov. de Catamarca). Trabajo Final de Carrera de Arqueología. Inédito. Facultad de Ciencias Naturales e Instituto Miguel Lillo, Universidad Nacional de Tucumán. 2001 b. El hogar, los ancestros y el corral: reocupación y variabilidad en el uso del espacio en unidades domésticas arqueológicas. Sitio Punta de la Peña 9 (Antofagasta de la Sierra, Catamarca). En Actas del XIV Congreso Nacional de Arqueología Argentina. Rosario, en prensa. 2005. Estructuras, representaciones y contextos. Perspectivas teórico metodológicas para el análisis de textiles arqueológicos. En V. Solanilla (Ed.) Demestre Tejiendo sueños en el Cono Sur: Textiles Andinos: Pasado, Presente y Futuro, 59-82, Centro de Estudios Precolombinos (CEP), Barcelona.

2006. De un hogar en la Puna... Historias de idas y vueltas. En M. E. Albeck, C. Scattolin y M. A. Korstanje (Eds.) El hábitat prehispánico. Arqueología de la arquitectura y de la construcción del espacio organizado, editado por, Universidad Nacional de Jujuy, Jujuy, en referato.

López Campeny, S. M. L.; D. Olivera; V. Fernández Varela y J. Peña 2005. Procesos Tafonómicos, Subsistencia y Uso del Espacio: Análisis de la arqueofauna de un sitio agropastoril de la Puna Meridional Argentina (Punta de La Peña 9, Antofagasta de la Sierra, Catamarca). Intersecciones en Antropología 6: 11-28.

Macko, S. A.; M. H. Engel; V. Andrusevich; G. Lubec; T. C. O'Connell and R.E.M. Hedges 1999a. Documenting the diet in ancient human populations through stable isotope analysis of hair. Phil. Trans. R. Soc. Lond. B 354: 65-76.

Macko, S. A.; G. Lubec; M. Teschler-Nicola;V. Andrusevich and M. H. Engel

$1999 \mathrm{~b}$. The Ice Man's diet as reflected by the stable nitrogen and carbon isotopic composition of his hair. The FASEB Journal 13: 559-562. 
Macko, S. A.; Araníbar, J.; Colaneri, M. G.; Zurita R. y C. A. Aschero.

2001. La dieta del bebé de la Peña. En Actas del XIV Congeso Nacional de Arqueología Argentina. Rosario, en prensa.

Novellino, P.y R. Guichón

1999. Primeros resultados de isótopos estables para el sur mendocino. Revista Argentina de Antropología Biológica 2: 323-334.

Olivera, D.

1992. Tecnología y estrategias de adaptación en el Formativo (Agro-alfarero Temprano) de la Puna Meridional Argentina. Un caso de estudio: Antofagasta de la Sierra (Pcia. de Catamarca, R.A.). Tesis de Doctorado. Inédita. Universidad Nacional de la Plata.

2006. Recursos bióticos y subsistencia en sociedades agropastoriles de la Puna Meridional Argentina. Comechingonia 9: 19-55.

Rees, C. E., W. J. Jenkins y J. Monster

1978. The sulphur isotopic composition of ocean water sulfate. Geochimica et Cosmochimica Acta 42: 377-381.

Reigadas, M. C.

1995. Criterios metodológicos para la detección del proceso de domesticación de camélidos en el NOA a partir del análisis microscópico de fibras y cueros arqueológicos. Cuadernos $\mathrm{N}^{\mathrm{o}}$ 5, FHYCS, Universidad Nacional de Jujuy.

1996. El beneficio de la lana. Variabilidad tecnológica en manufacturas textiles actuales y arqueológicas en Susques (Prov. De Jujuy). XXV Aniversario del Museo Arqueológico Dr. Eduardo Casanova. Instituto Interdisciplinario de Tilcara. Facultad de Filosofía y Letras. UBA.

Rodríguez, M. F.

2006. Presencia de especies vegetales $C_{3} / C_{4}$ en sitios arqueológicos de la Puna Meridional Argentina, Antofagasta de la Sierra, Catamarca. Ponencia presentada en el Taller Arqueología e Isótopos Estables en el Sur de Sudamérica, Malargüe, Mendoza (manuscrito en posesión de los autores).

Sprent, J. I.

1995. Legume trees and shrubs in the tropics: $\mathrm{N}_{2}$ fixation in perspective. Soil Biology and Biochemistry 27, 401-407.

Tieszen, L. L., T. W. Boutton, K. G. Tesdahl, y N. A. Slade 1983. Fractionation and turnover of stable carbon isotopes in animal tissues: implications for ${ }^{13} \mathrm{C}$ analysis of diet. Oecologia 57: 32-37.

Tieszen, L. L. y T. W. Boutton 1989. Stable carbon isotopes in terrestrial ecosystem research. En P. W. Rundel, J. R. Ehleringer y K. A. Nagy (Eds.) Stable Isotopes in Ecological Research, Springer-Verlag, New York.

Van Der Merwe, N. J., Lee-Thorp, J. A. and J. Scott Raymond 1993. Light, stable isotopes and the subsistence base of formativa cultures at Valdivia, Ecuador. En: Lambert, J. and G. Groupe (Eds.) Prehistoric Human Bone. Archaeology at the Molecular level. Springer Verlag, Berlín - Heidelberg - New York. 
Yesner, D., M. J. Figuerero Torres, R. A. Guichón y L. A. Borrero 1991. Análisis de isótopos estables en esqueletos humanos: confirmación de patrones de subsistencia etnográficos para Tierra del Fuego. Shincal 3: 182-191. 